\title{
Fusion to green fluorescent protein improves expression levels of Theileria parva sporozoite surface antigen p67 in insect cells
}

\author{
S. A. KABA ${ }^{1,2}$, V. NENE ${ }^{2} \uparrow$, A. J. MUSOKE ${ }^{2}$ J. M. VLAK ${ }^{1}$ and M. M. van OERS ${ }^{1 *}$ \\ ${ }^{1}$ Laboratory of Virology, Wageningen University, Binnenhaven 11, 6709 PD, Wageningen, The Netherlands \\ ${ }^{2}$ International Livestock Research Institute, P.O. Box 30709, Nairobi, Kenya
}

(Received 27 April 2002; revised 22 fuly 2002; accepted 23 fuly 2002)

S UMMAR Y

East Coast fever (ECF) is a fatal disease of cattle caused by the protozoan parasite Theileria parva. The development of a subunit vaccine, based on the sporozoite-specific surface antigen $\mathrm{p} 67$, has been hampered by difficulties in achieving highlevel expression of recombinant p67 in a near-authentic form. Therefore two sets of recombinant baculovirus vectors were constructed. The first set, encoding various regions of p67, produced low levels of the corresponding p67 domains in High Five $^{\mathrm{TM}}$ cells, despite the presence of large amounts of p67 RNA. The second, consisting of p67 domains fused to the carboxy-terminus of GFP expressed significantly higher levels of p67 protein. The GFP:p67 fusion proteins were recognized by a sporozoite-neutralizing monoclonal antibody (TpM12) raised against native p67 whereas non-fused full length p67 expressed in insect cells was not recognized. GFP-tagging therefore, appeared to enhance the stability of p67 and to conserve its folding. The high-level expression of p67 domains in a more authentic form is an important step towards the development of an effective subunit vaccine against ECF.

Key words: Theileria parva, sporozoite surface antigen, GFP, baculovirus expression system, East Coast fever.

\section{INTRODUCTION}

Theileria parva is a tick-transmitted protozoan parasite of cattle, which causes East Coast fever (ECF). This disease is of major economic importance throughout east, central and southern Africa. The brown ear tick, Rhipicephalus appendiculatus, transmits the sporozoite stage of the parasite. The sporozoites enter host lymphocytes where they develop into intracellular multinucleate schizonts resulting in a fatal lymphoproliferative and destructive disease (for reviews see Norval, Perry \& Young, 1992; Dobbelaere \& Heussler, 1999).

The sporozoite surface protein p67 synthesized during sporogony within the tick plays an essential role in the invasion process (Dobbelaere \& Spooner, 1985 ; Dobbelaere, Shapiro \& Webster, 1985 ; Dobbelaere et al. 1985). Monoclonal antibodies directed against p67 block (Dobbelaere et al. 1984), and soluble p67 competitively inhibits (Shaw et al. 1995) invasion of bovine lymphocytes by the sporozoites. P67 contains 709 amino acid residues and has the characteristics of a transmembrane protein. It has a secretory signal sequence at the N-terminus, 7

* Corresponding author: Laboratory of Virology, Wageningen University, Binnenhaven 11, 6709 PD, Wageningen, The Netherlands. Tel: +31317485082. Fax: + 31317 484820. E-mail:monique.vanoers@wur.nl

$\dagger$ Current address: The Institute for Genomic Research, Rockville, USA. potential $N$-linked glycosylation sites and a hydrophobic C-terminal tail (Nene et al. 1992). P67 is conserved among sporozoites isolated from different cattle-derived T. parva stocks (Nene et al.1996), thus making it a good candidate for a broad-spectrum subunit vaccine against ECF.

To investigate its vaccine potential, p67 has been cloned and expressed in Escherichia coli (Musoke et al. 1992) as a fusion to the non-structural NS1 protein of influenza virus A. Cattle immunized with NS1-p67 generated high titres of p67-specific antibodies with a strong in vitro neutralizing activity against $T$. parva sporozoites. On challenge with $\mathrm{LD}_{70}$ of stabilated sporozoites, $70 \%$ of the immunized cattle were protected against ECF. A relatively high dose of NS1-p67 was required to achieve this level of protection. In addition NS1-p67 was not recognized by TpM12, a neutralizing monoclonal antibody raised against native p67 (Musoke et al. 1984). These observations indicate that the $E$. coli-expressed p67 was not in a native conformation or that it lacked characteristic post-translational modifications, such as glycosylation, which might be required for complete protective immune responses.

The baculovirus-insect cell expression system has been used in an attempt to express p67 in more authentic forms with the proper folding and modifications (Nene et al. 1995). Attempts to generate a full-length p67 in insect cells were frustrated by the fact that recombinant $\mathrm{p} 67$ was produced at a low 
level, the product was only partially processed and not transported to the cell membrane. This insect cell-derived p67 was essentially produced in a nonnative form. Cattle immunized with the baculovirusderived p67 showed a similar response to animals immunized with the NS1-p67 product. The lack of sufficient quantities of near-authentic recombinant p67 hampers the evaluation of the full potential of $\mathrm{p} 67$ as a vaccine (Nene et al. 1995). Waldo et al. (1999) first suggested that green fluorescent protein (GFP) might enhance stability of GFP fusion proteins. Indeed, in prokaryotic expression systems, GFP-tagging increased both stability and solubility of recombinant proteins (Rucker et al. 2001). Since the first expression of GFP with recombinant baculoviruses (Reilander, Haase \& Maul, 1996), GFP has been widely used as a fluorescence marker for gene expression, protein localization and trafficking, and protein-protein interactions by fusing its coding sequence to that of the protein of interest (Wilson et al. 1997).

In this study we sought to evaluate whether GFP fusion could enhance the stability and hence the expression levels of p67 in insect cells as well as induce/preserve its native conformation, by expressing various p67 subdomains either as separate open reading frames (ORFs) or as $\mathrm{C}$-terminal fusions to GFP. We report here the high-level expression of p67 domains in a more authentic form in insect cells.

MATERIALS AND METHODS

\section{Cells and viruses}

Trichoplasia $n i$ High-Five ${ }^{\mathrm{TM}}$ insect cells (Invitrogen) were maintained in Grace's supplemented insect medium (Invitrogen) with $10 \%$ foetal bovine serum (FBS) as monolayer cultures at $27^{\circ} \mathrm{C}$. For routine cell maintenance, propagation and virus infection, standard procedures were followed (Summers \& Smith, 1987; King \& Possee, 1992). As control viruses the Autographa californica multicapsid nucleopolyhedrovirus (AcMNPV), strain E2 (Smith, Vlak \& Summers, 1983), and the recombinant baculovirus, BEV-p67 (Nene et al. 1995) were used. BEV-p67 is a recombinant baculovirus carrying the complete p67 protein including its native signal and transmembrane sequences.

\section{Construction of recombinant baculoviruses}

Theileria parva cDNA sequences (Fig. 1A) encoding the $\mathrm{N}$-terminus $\left(\mathrm{p} 67 \mathrm{~N}_{21-225}\right.$ ), the central region (p67 $\left.\mathrm{M}_{226-571}\right)$, the $\mathrm{C}$-terminus $\left(\mathrm{p} 67 \mathrm{C}_{572-651}\right)$ as well as the full-length p67 protein $\left(\mathrm{p} 67 \Delta \mathrm{SS}_{21-651}\right)$ were PCR-amplified from a pMG1-p67 clone (Musoke et al. 1992) using extended primers that introduced $B s s \mathrm{HII} / S a l \mathrm{I} / S s t \mathrm{I}$ or HindIII/ClaI restriction sites (see Table 1). In contrast to the complete p67 protein expressed by recombinant BEV-p67 (Nene et al. 1995), the p67 $\Delta \mathrm{SS}$ domain excluded the authentic p67 signal and transmembrane anchor sequences. The PCR products were cloned into pGEM-T (Promega) and sequences of the inserts were verified by automated sequencing.

The DNA sequence encoding GFP was amplified from a pBluescript-GFP clone (kindly provided by Gerard van der Krogt; Laboratory of Molecular Biology, Wageningen University) by using extended primers to intoduce $N c o \mathrm{I} / N s i \mathrm{I}$ or BamHI-ClaI/ HindIII-Sst I sites (Table 1). The PCR products were cloned into pGEM-T (Promega). GFP was re-cloned into the plasmids pFastBacDual (pFBD) and $\mathrm{pFastBacHTb}$ (pFBhis) (Invitrogen). GFP was cloned as NcoI-NsiI fragment downstream of the p10 promoter in pFastBacDual generating the parental plasmid, pFBDp10GFP (Fig. 1B; 1), for nonfused expression. In the pFastBacHT vector, GFP was cloned as BamHI-Sst I fragment generating the parental plasmid for the GFP fusions, pFBhisGFP (Fig. 1C; 1).

To generate non-fused constructs, p67C, p67N and $\mathrm{p} 67 \mathrm{M}$ were cloned as SstI-HindIII fragments downstream of the polyhedrin promoter in the pFBDp10GFP vector, generating the donor plasmids: pFBDp10GFP-php67C, pFBDp10GFPphp67N and pFBDp10GFP-php67M (Fig. 1B; 2, 3,4 respectively). Cloning of the $\mathrm{p} 67$ domains as Sst I-HindIII fragments into the pFBhisGFP vector resulted in in-frame end-to-end gene fusion of the p67 domains to the C-terminus of GFP, generating the GFP : p67 fusion constructs : $p F B$ hisGFP : p67C, pFBhisGFP:p67N, pFBhisGFP:p67M and pFBhisGFP : p67 $\Delta$ SS (Fig. 1C; 2, 3, 4, 5). Recombinant baculoviruses encoding the non-fused p67 protein domains were generated via the Bac-to-Bac ${ }^{\mathrm{TM}}$ baculovirus expression system (Luckow et al. 1993; Invitrogen), resulting in Ac-p67N, Ac-p67M, Acp67C and the control virus Ac-GFP. The recombinant baculoviruses Ac-hisGFP : p67N, Ac-hisGFP : p67M, Ac-hisGFP : p67C, Ac-hisGFP : p67 $\Delta$ SS encoding the fusion proteins and the control, AchisGFP were also generated.

\section{Protein analysis}

For the analysis of recombinant protein expression, $1 \times 10^{6} T$. ni High Five ${ }^{\text {TM }}$ cells were seeded into $35 \mathrm{~mm}^{2}$ Petri dishes and infected with the various recombinant viruses at a multiplicity of infection (MOI) of 10 plaque-forming units (pfu) per cell. At $72 \mathrm{~h}$ post-infection (p.i.) cells were harvested and washed in $1 \mathrm{ml}$ of phosphate-buffered saline (PBS) at $4{ }^{\circ} \mathrm{C}$. Finally the pellet was re-suspended in $100 \mu \mathrm{l}$ of ice-cold PBS. Protein concentrations were determined using Bradford reagent (Bio-Rad). Samples containing $2.5 \mu \mathrm{g}$ total protein were analysed in $15 \%$ (non-fused samples) or $10 \%$ (fusion 


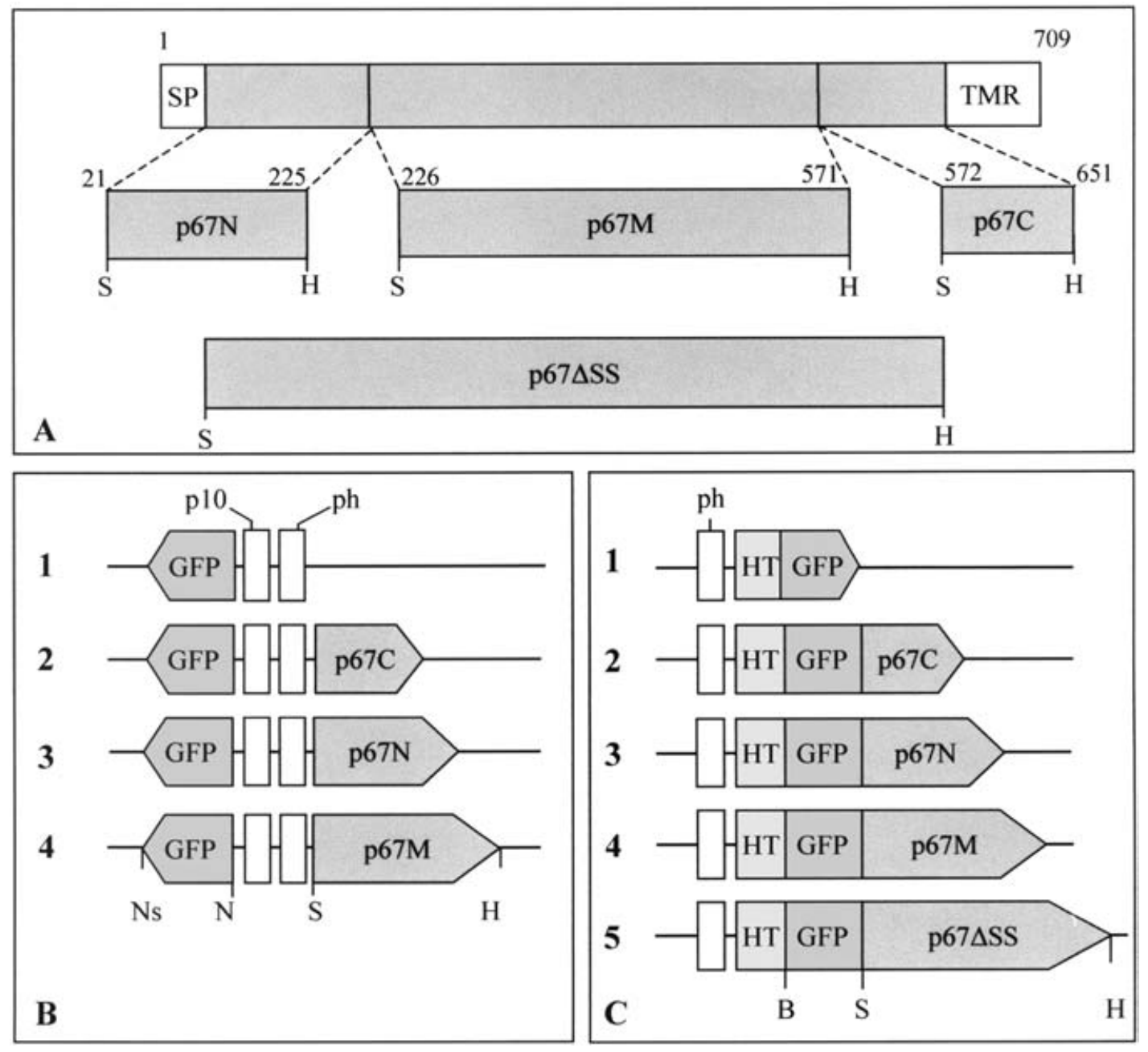

Fig. 1. Schematic representation of non-fused p67 (B) and GFP:p67 (C) fusion constructs. (A) The Theileria parva p67 open reading frame: SP (amino acid 1-20) is the p67 signal peptide; p67N (amino acid 21-225) the amino terminus; p67M (amino acid 226-571) the middle region; p67C (amino acid 572-651) is the carboxy terminus and TMR represents the transmembrane region. (B) The various pFastBacDual constructs: GFP was inserted as a NcoI-NsiI fragment downstream of the p10 promoter while the various p67 domains were inserted as HindIII-SstI fragments under the transcriptional control of the polyhedrin (ph) promoter. (C) The various GFP : p67 fusion constructs. GFP was first cloned into the pFastBacHTb vector as BamHI-Sst I fragment to generate the vector pFBhisGFP. The various p67 domains were then inserted into the pFBhisGFP vector as SstI-HindIII fragments resulting in an end-to-end gene fusion of the p67 domains to the C-terminus of GFP. The pFastBacHTb vector encodes a hexa-polyhistidine sequence allowing N-terminal His-tagging of the foreign protein to facilitate purification. $\mathrm{S}=S s t \mathrm{I}, \mathrm{H}=H i n \mathrm{dIII}, \mathrm{Ns}=N s i \mathrm{I}$, $\mathrm{N}=$ NcoI, B = Bam HI.

proteins) SDS-PAGE gels, as described by Laemmli (1970). Proteins were visualized by Coomassie Brilliant blue $(\mathrm{CBB})$ staining or subjected to Western analysis. Monoclonal antibodies, ARIII 22.7 and ARIII 21.4 (Nene et al. 1999) specific for p67N and $\mathrm{C}$ respectively, were used. The polyclonal antibodies, rabbit Rat 44 and bovine BJ 36 (Nene et al. 1999) raised against the complete p67 protein were used for $\mathrm{p} 67 \mathrm{M}$ and $\mathrm{p} 67 \Delta \mathrm{SS}$ respectively. All antibodies were used at a dilution of $1: 200$. For the GFP : p67 fusion proteins, monoclonal antibodies against the polyhistidine tag (Sigma) or a polyclonal antibody against GFP (both at a dilution of $1: 5000$ ) were used. As the second antibody, rabbit anti- mouse immunoglobulins (for the monoclonals), antibovine immunoglobulins (for BJ 36), or swine antirabbit immunoglobulins (for the $\alpha \mathrm{GFP}$ ) conjugated to horseradish peroxidase (HRP) (DAKO, A/S, Denmark) were used at a dilution of $1: 5000$. The HRP substrate, 4-chloro-1-naphthol (Bio-Rad) was used to detect the p67 recombinant proteins.

\section{Purification and dot blot analysis}

The polyhistidine tag was exploited to purify the fusion proteins using TALONspin IMAC columns (CLONTECH Laboratories). High Five ${ }^{\text {TM }}$ insect cells were infected with the recombinant viruses at 


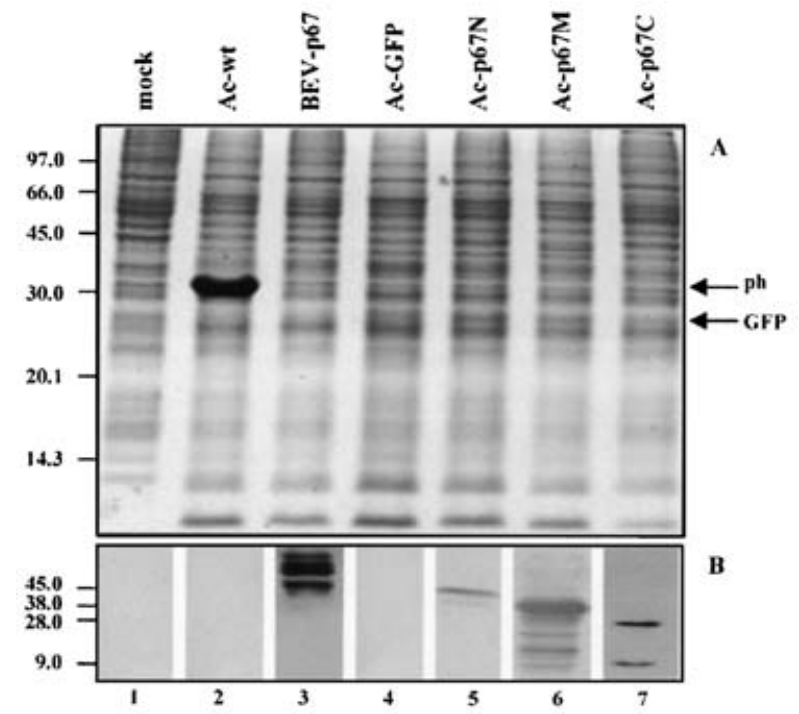

Fig. 2. SDS-PAGE and Western blot analysis of non-fused p67 proteins. Trichoplusia ni High Five ${ }^{\mathrm{TM}}$ insect cells were mock-infected (lane 1) or infected with Ac-wt virus (lane 2) or recombinant viruses BEV-p67 (lane 3), Ac-GFP (lane 4), Ac-p67N (lane 5), Ac-p67M (lane 6), Ac-p67C (lane 7) and harvested at $72 \mathrm{~h}$ p.i. Total protein $(2 \cdot 5 \mu \mathrm{g})$ was resolved in $15 \%$ SDS-PAGE and stained with Coomassie Brilliant blue (A) or subjected to immunoblot analysis using the p67N-specific monoclonal antibody ARIII 22.7, the p67M-specific polyclonal antibody Rat 44 or the p67C-specific monoclonal antibody ARIII 21.4 (B).

a MOI of 10 pfu per cell and collected at $72 \mathrm{~h}$ p.i. Cells were concentrated and clarified cytoplasmic extracts were applied to the columns. After washing with buffer $(50 \mathrm{~mm}$ sodium phosphate, $300 \mathrm{~mm} \mathrm{NaCl}$, $\mathrm{pH} 7 \cdot 0$ ) containing $25 \mathrm{~mm}$ imidazole to remove unbound and weakly bound proteins, the polyhistidine-tagged GFP : p67 fusion proteins were eluted from the column by increasing the imidazole concentration to $200 \mathrm{~mm}$.

To examine the antigenic authenticity of the insect cell-derived GFP : p67 fusion proteins, dot blot analysis was performed. Five $\mu \mathrm{g}$ of the purified GFP : p67 fusion proteins and $10 \mu \mathrm{g}$ of total cell lysate of infected T. $n i$ High Five ${ }^{\text {TM }}$ insect cells were spotted on a nitrocellulose membrane and allowed to dry. Proteins were denatured by adding $1 / 20$ volume of $\beta$-mercaptoethanol and $1 / 4$ volume of 4 -fold sample buffer (40 mu Tris-HCl, pH 8·0, 4 mu EDTA, $8 \%$ SDS) and incubation at $95{ }^{\circ} \mathrm{C}$ for $10 \mathrm{~min}$. Duplicate blots were incubated with TpM12 $(1: 50)$ or ARIII $22.7(1: 200)$ for $1 \mathrm{~h}$ at room temperature, washed and further incubated with goat anti-mouse immunoglobulins conjugated with horseradish peroxidase (Amersham) at a dilution of 1:5000. Enhanced chemiluminescence (ECL) (Amersham) was used for detection. The insect cell-derived p67 expressed by Nene et al. (1995), indicated as BEVp67, was compared with these GFP:p67 fusion 

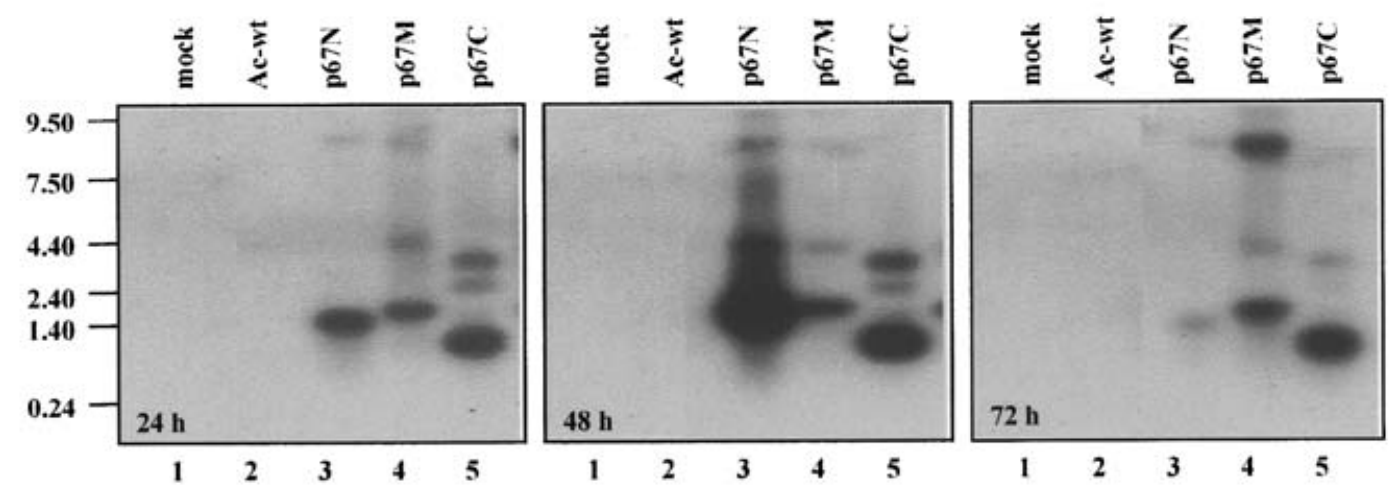

Fig. 3. Northern blot analysis of non-fused p67 transcripts. Total RNA (5 $\mu \mathrm{g})$ was extracted from mock-infected Trichoplusia $n i$ High Five ${ }^{\text {TM }}$ insect cells (lanes 1), or cells infected with Ac-wt virus (lanes 2) or the recombinant viruses Ac-p67N (lanes 3), Ac-p67M (lanes 4), Ac-p67C (lanes 5) at 24, 48 or $72 \mathrm{~h} \mathrm{p.i.} \mathrm{Total} \mathrm{RNA} \mathrm{was} \mathrm{resolved} \mathrm{in} \mathrm{a} 1.4 \%$ agarose gel and transferred to a Nylon filter. The filter was hybridized to a radioactively labelled p67 DNA probe. The film was exposed overnight. The sizes of an RNA marker are indicated in kilobases.

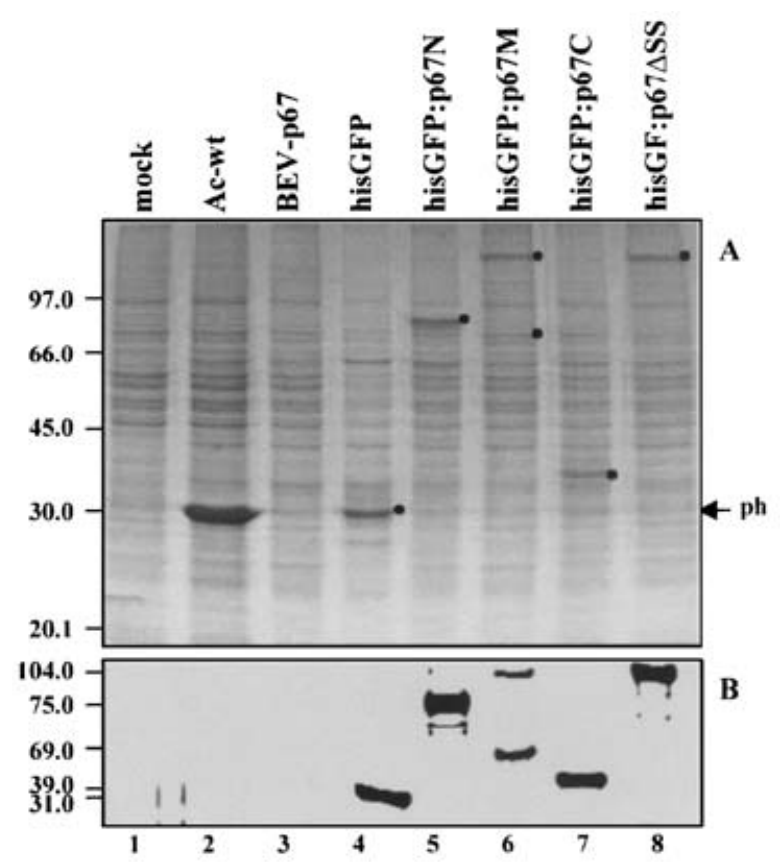

Fig. 4. SDS-PAGE and Western blot analysis of GFP : p67 fusion proteins. Trichoplasia ni High Five $^{\mathrm{TM}}$ insect cells (lane 1) were infected with the Ac-wt virus (lane 2), or recombinant viruses BEV-p67 (lane 3), Ac-hisGFP (lane 4), Ac-hisGFP : p67N (lane 5), Ac-hisGFP : p67M (lane 6), Ac-hisGFP : p67C (lane 7), Ac-hisGFP : p67 $\Delta$ SS (lane 8 ) and harvested at $72 \mathrm{~h}$ p.i. Proteins $(2.5 \mu \mathrm{g})$ were resolved in 10\% SDS-PAGE and stained with Coomassie Brilliant blue (A) or subjected to immunoblot analysis using a monoclonal antibody against the hexa-Histidine tag (B). The dots (in A) indicate the various GFP fusion proteins.

proteins. The same amount $(5 \mu \mathrm{g})$ of purified $E$. coli-expressed $\mathrm{p} 67 \mathrm{~N}$, and hisGFP proteins as well as mock and Ac-wt infected cell lysates containing $10 \mu \mathrm{g}$ total protein were used as controls.

\section{Transcript analysis}

T. $n i$ High Five ${ }^{\mathrm{TM}}$ insect cells $\left(1 \cdot 0 \times 10^{6}\right)$ were infected with the recombinant viruses Ac-p67N, Acp67M, Ac-p67C, and Ac-GFP at a MOI of $10 \mathrm{pfu} /$ cell and harvested at 24,48 and $72 \mathrm{~h}$ p.i. Total RNA was isolated using the single-step acid guanidinium thiocyanate-phenol-chloroform RNA extraction method described by Chomczynski \& Sacchi (1987). Five ng RNA were resolved in $1.4 \%$ agarose gel and Northern blot analysis was carried out as described in Pellé \& Murphy (1993). The RNA was fixed to the filter by UV light cross-linking. The filter was hybridized to a PCR-amplified p67 (full length) probe, labelled with $\alpha^{32} \mathrm{P}-\mathrm{dCTP}$ by random primed labelling with Klenow (Promega).

\section{RESULTS}

\section{Expression of p67 subdomains in insect cells}

To enhance the expression levels of p67 in insect cells, subregions of p67 rather than the complete p67 protein (Nene et al. 1995) were expressed. The domains of p67 expressed in this study were an $\mathrm{N}$-terminal domain $\left(\mathrm{p} 67 \mathrm{~N}_{21-225}\right)$, the central region $\left(\mathrm{p} 67 \mathrm{M}_{226-571}\right)$ and a C-terminal domain (p67 $\left.\mathrm{C}_{572-651}\right)$ as well as the full-length protein without its native signal sequence and transmembrane region $\left(\mathrm{p} 67 \Delta \mathrm{SS}_{21-651}\right)$ (Fig. 1A). The p67N, p67M and $\mathrm{p} 67 \mathrm{C}$ domains were cloned and expressed as separate open reading frames (non-fused constructs) (Fig. 1B). In a second experiment, each p67 domain was fused to the C-terminus of GFP and expressed as a fusion protein (Fig. 1C).

T. $n i$ High Five ${ }^{\mathrm{TM}}$ cells infected with recombinant viruses encoding these different p67 subdomains (non-fused and fused) were analysed in SDS-PAGE and stained with Coomassie Brilliant blue (CBB) or 

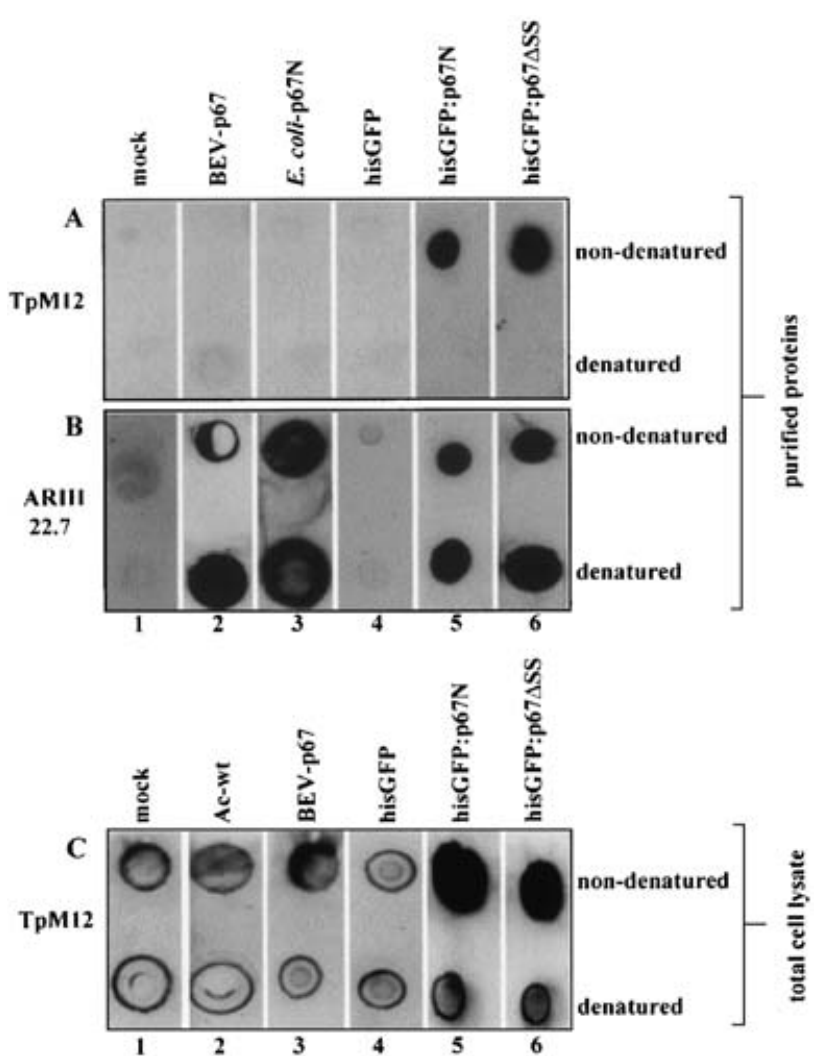

Fig. 5. Immuno-dot-blot analysis of hisGFP : p67 fusion proteins. Both non-denatured and denatured purified proteins $(A$ and $B$ ) or total cell lysate $(C)$ of hisGFP : p67N and hisGFP : p67 $\Delta \mathrm{SS}$ were spotted on a nitrocellulose membrane and subjected to immunoblot analysis using monoclonal TpM12 or ARIII 22.7. TpM12 was raised against native $\mathrm{p} 67$ while ARIII 22.7 was raised against E. coli-derived p67.

subjected to immunoblot analysis. In the Coomassiestained gel of the non-fused p67 recombinants, the p67 subdomains p67N, p67M and p67C could not be detected (Fig. 2A, lanes 5-7). A protein with the expected electrophoretic mobility for GFP was observed for all recombinants (Fig. 2A, lanes 4-7). The medium of cells infected with Ac-GFP, Ac-p67N, Ac-p67M and Ac-p67C turned green as early as $24 \mathrm{~h}$ p.i. GFP expression was confirmed by the green fluorescence of the protein under UV-light and by Western blot analysis using $\alpha \mathrm{GFP}$ polyclonal antibody (DAKO) (results not shown), indicating that the infection had been successful. These results indicate that the expression levels for the subdomains were not significantly increased compared to the fulllength p67 (Nene et al. 1995) expressed in insect cells (Fig. 2A, lane 3).

In immuno-blot analysis a reaction with p67 antibodies was observed for BEV-p67 which was absent in the mock, Ac-wt and Ac-GFP samples (Fig. 2B, lanes 1-4). The monoclonal antibodies, ARIII 22.7, RAT 44 and ARIII 21.4, directed against p67N, $\mathrm{p} 67 \mathrm{M}$ and $\mathrm{p} 67 \mathrm{C}$, respectively, showed that $\mathrm{p} 67 \mathrm{~N}$, $\mathrm{p} 67 \mathrm{M}$ and $\mathrm{p} 67 \mathrm{C}$ proteins were expressed, although at low levels, since they could not be detected by Coomassie staining (Fig. 2A). P67M and to a lesser extent p67N showed degradation (Fig. 2B, lanes $5-7)$. The major product of $\mathrm{p} 67 \mathrm{~N}$ was detected as a $45 \mathrm{kDa}$ protein instead of the expected $22 \mathrm{kDa}$ (Fig. 2B, lane 5). In Ac-p67M infected cells a $38 \mathrm{kDa}$ protein was detected as expected for $\mathrm{p} 67 \mathrm{M}$ protein (Fig. 2B, lane 6). P67C was detected as 2 separate major proteins of $8.6 \mathrm{kDa}$, the expected mobility for $\mathrm{p} 67 \mathrm{C}$, and of $28.0 \mathrm{kDa}, 3$ times the predicted size of p67C (Fig. 2B, lane 7).

To investigate whether the low level of expression of p67 domains observed was due to low transcription, we examined p67 transcripts at different times post-infection. Total RNA was purified from cells mock-infected or infected with Ac-wt, Ac-p67N, Ac-p67M and Ac-p67C viruses and subjected to Northern blot analysis using a p67-specific probe. The p67 probe did not hybridize to mRNA purified from mock and Ac-wt infected cells (Fig. 3, lanes 1 and 2 ). In the recombinant virus-infected cells, p67 transcripts were easily detected at $24 \mathrm{~h}$ p.i. and the amount increased at $48 \mathrm{~h}$ p.i. Transcripts were still observed at 72 h p.i. (Fig. 3, lanes 3-5). The amount of transcript was, however, not reflected in the level of p67 proteins observed (see Fig. 2A), suggesting that the low level of expression of p67 subdomains might be due to instability of the end-products.

To overcome this problem, p67 subdomains were expressed as carboxy-terminal fusion proteins to GFP (Fig. 1C). T. $n i$ High Five $^{\text {TM }}$ cells were infected with the recombinant baculoviruses Ac-hisGFP, AchisGFP : p67N, Ac-hisGFP : p67M, Ac-hisGFP : p67C, Ac-hisGFP : p67 $\Delta S S$ and total proteins from infected cell lysates were resolved in SDS-PAGE and stained with $\mathrm{CBB}$ or subjected to immunoblot analysis. In the control lanes no $\mathrm{p} 67$-specific proteins were observed (Fig. 4A, lanes 1-4). A $31 \mathrm{kDa}$ protein corresponding to the predicted size of hisGFP was observed for Ac-his GFP (Fig. 4A, lane 4). With the fusion constructs, significantly higher levels of expression of $\mathrm{p} 67$ recombinant fusion proteins were observed in the CBB-stained gel (Fig. 4A, lanes 5-8) as compared to the non-fused proteins (Fig. 2A) since they were easily seen in the Coomassie-stained gels. The hisGFP : p67N fusion protein (lane 5) migrated as a $75 \mathrm{kDa}$ protein as opposed to a predicted size of $53 \mathrm{kDa}$. His GFP : p67M was expressed in 2 forms, the expected $69 \mathrm{kDa}$ protein and a $104 \mathrm{kDa}$ protein (Fig. 4B, lane 6). HisGFP : p67C was expressed as a $39 \mathrm{kDa}$ protein (Fig. 4B, lane 7) and his GFP : p67 $\Delta \mathrm{SS}$ as a $104 \mathrm{kDa}$ protein (Fig. 4B, lane 8) as expected.

A monoclonal antibody directed against the $\mathrm{N}$ terminal hexa-histidine tag $(\mathrm{CLONTECH})$ was used to confirm expression of all the fusion proteins in an immuno-blot analysis. All the fusion proteins were detected at the same size as observed in the protein gel (Fig. 4B, lanes 4-8). Western blot analysis using 
either a polyclonal antibody against GFP or monoclonal antibodies directed against the different p67 domains gave similar results (not shown).

\section{Conformation of p67 fusion proteins}

The GFP-p67 fusion proteins were purified and the SDS-PAGE analysis of eluted fractions showed that the polyhistidine tagged proteins were efficiently bound to the column and that the fractions contained highly purified proteins (results not shown). An immuno-dot blot analysis was performed to investigate whether the GFP-tagging affected the folding of the p67 domains in the fusion protein. A monoclonal antibody, TpM12, raised against native $\mathrm{p} 67$, and which does not recognize $E$. coli-derived p67 (Musoke et al. 1984), was used as the first antibody in this analysis. Purified proteins as well as total cell lysate of cells infected with AchisGFP:p67N and AchisGFP:p67 $\triangle \mathrm{SS}$ were spotted on the blot. As controls, we used hisGFP, BEV-p67 and E. coliderived $\mathrm{p} 67 \mathrm{~N}$ as well as a mock-infected cell lysate. Both denatured and non-denatured samples were analysed. As a control measure a duplicate blot was incubated with the monoclonal antibody, ARIII 22.7, that was raised against denatured p67 and which recognizes a linear epitope in the $\mathrm{N}$-domain (Nene et al. 1999). TpM12 did not react with proteins (both denatured and non-denatured) in the mock, the BEV-p67, E. coli-derived p67N and the hisGFP samples (Fig. 5A, lanes 1-4). TpM12 reacted with non-denatured but not with the denatured samples of hisGFP : p67N and hisGFP : p67 $\triangle \mathrm{SS}$ (Fig. 5A, lanes 5 and 6), indicating that the GFP-p67 fusion proteins were expressed in a near-native conformation. All the protein samples (both denatured and non-denatured) except for the negative controls reacted with ARIII 22.7 (Fig. 5B, lanes 1-6), confirming that $\mathrm{p} 67$-specific proteins had been spotted on all blots.

\section{DISCUSSION}

Low expression levels of $T$. parva p67 were observed by Nene et al. (1995) in their attempt to produce large amounts of p67 in a more authentic form via the baculovirus-insect cell expression system. In the present study we expressed subdomains of $T$. parva sporozoite $\mathrm{p} 67$ instead of the complete $\mathrm{p} 67$ protein to obtain higher levels of expression. First, we expressed p67 subdomains as non-fused proteins and in a second experiment, as fusions to the C-terminus of GFP. In both groups the native p67 signal peptide and transmembrane region were eliminated as this might limit expression levels (Li et al. 1994). Pepscan and computer analyses have predicted that antigenic sites of p67 were located in the $\mathrm{N}$ - and $\mathrm{C}$-terminal regions (Knight et al. 1996; Nene et al. 1999). Antibody responses of bovines to $\mathrm{p} 67$ are restricted to these two domains (Knight et al. 1996; Nene et al. 1999). Although the middle region of p67 does not appear to have linear B-cell epitopes, it contains several Th-cell epitopes (Musoke, Nene \& McKeever, 1995). The middle region was included in this study since it could be used to define T-cell epitopes when it becomes necessary to investigate the protective capacity of peptide-based vaccines in the future.

The non-fused proteins were expressed at a low level as was the full-length p67 protein (Nene et al. 1995). This may be due to inefficient translation of p67 transcripts or the instability of nascent p67 proteins since abundant transcripts were detected by Northern blot analysis. A similar problem was seen in E. coli, where p67 expressed as fusion to the glutathione-S-transferase of Schistosoma japonicum (Nene et al. 1992) and the non-structural protein-1 (NS1) of influenza virus A (Musoke et al. 1992) have failed to produce stable recombinant p67 protein.

A significantly higher level of expression of the p67 domains was obtained when fused to GFP, relative to the non-fused as well as full-length p67 (Nene et al. 1995). Fusion to GFP either enhanced translation or, more likely, improved the stability of the p67 nascent protein products, thereby increasing the yield of p67 expression in insect cells. GFP has been shown to enhance the stability and increase the expression of fusion proteins in prokaryotic expression systems (Waldo et al. 1999; Rucker et al. 2001). Another indication that GFP could stabilize a fused protein was obtained by Akgul et al. (2000), when they deleted a stability-regulating motif (the PEST sequence) from the Mc-1 protein (Sato et al. 1994; Sedlak et al. 1995) but did not find any effect on the stability of a Mcl-GFP fusion protein.

The observed molecular mass of the hisGFP: p67N, hisGFP : p67M and hisGFP : p67 $\triangle \mathrm{SS}$ recombinant fusion proteins in SDS-PAGE was considerably higher than the calculated value. For example the apparent molecular mass of hisGFP:p67N was $75 \mathrm{kDa}$ as opposed to the predicted size of $53 \mathrm{kDa}$. The exact reason for the anomalous behaviour of these recombinant proteins in SDS-PAGE is not clear. It is known that p67 undergoes $N$-glycosylation in insect cells (Nene et al. 1995), but this could not explain the present observation since the signal peptide of p67 was eliminated in these constructs. The primary amino acid sequence of p67 may be responsible for the aberrant mobility since a similar difference between the observed and calculated molecular mass was observed for the non-fused p67 domains. Similar observations have been made with recombinant p67 production in both $E$. coli and insect cells (Nene et al. 1992, 1995).

A recombinant p67 in a near authentic form is highly desirable as it might function as a better immunogen than the previously tested NS1-p67 (Musoke et al. 1992; Nene et al. 1995). An immunodot-blot analysis using a monoclonal specific for 
native p67 indicated that GFP fusions of $\mathrm{p} 67 \mathrm{~N}$ and $\mathrm{p} 67 \Delta \mathrm{SS}$ had a near native folding, in contrast to the full length p67 expressed in insect cells in a non-fused form.

GFP is being used extensively as a visible marker in cell biology because it operates independently of cofactors and can be detected rapidly and easily. Due to its small size, GFP does not significantly increase the size of the chimeric protein neither does it interfere in general with the biological functions of even small proteins (Tsien, 1998; Stauber et al. $1998 a, b$; Carter \& Sorkin, 1998; Waldo et al. 1999). In this case, GFP fusion not only facilitated direct detection and monitoring of infected insect cells, and titration of recombinant viruses, it also increased expression levels of a recombinant protein, and appeared to conserve its natural folding properties. The high-level expression of near-authentic p67 domains is an important step towards the development of an effective subunit vaccine against $\mathrm{ECF}$. Investigation of the immunogenic properties of these products and determining the level of protection against ECF in cattle will be the next step towards evaluating the vaccine potential of these GFP : p67 fusion proteins.

The authors are thankful to Arno Vermeulen and Dick Schaap (Intervet International BV) for their invaluable advice. We are thankful to Magda Usmany, Stephen Wanyoni, Julius Osasa and James Gachanja, for their technical assistance and Aart van t' Oever for purifying the fusion proteins. Stephen A. Kaba was financed by the Netherlands Foundation for the Advancement of Tropical Research (WOTRO).

\section{REFERENCES}

AKGul, C., MOUlding, D. A., White, M. R. H. \& EDWARDS, S. W. (2000). In vivo localisation and stability of human Mc-1 using green fluorescent protein (GFP) fusion proteins. FEBS Letters $\mathbf{4 7 8}, \mathbf{7 2 - 7 6 .}$

CARTER, R. E. \& SORKIN, A. (1998). Endocytosis of functional epidermal growth factor receptor-green fluorescent protein chimera. Fournal of Biological Chemistry 273, 35000-35007.

CHOMCZYNski, P. \& SACCHI, N. (1987). Single-step method of RNA isolation by acid guanidinium thiocyanatephenol-chloroform extraction. Analytical Biochemistry 162, 156-159.

DOBbelaERE, D. \& HEUSSLER, v. (1999). Transformation of leukocytes by Theileria parva and T. annulata. Annual Review of Microbiology 53, 1-42.

Dobbelaere, D. A. E. \& SPOONER, P. R. (1985). Production in ascites fluid of biosynthetically labelled monoclonal antibody to Theileria parva sporozoites. Fournal of Immunological Methods 82, 209-214.

DOBbElaERE, D. A., SHAPIRO, S. Z. \& WEBSTER, P. (1985). Identification of a surface antigen on Theileria parva sporozoites by monoclonal antibody. Proceedings of the National Academy of Sciences, USA 82, 1771-1775.

DObBElaERE, D. A. E., SPOONER, P. R., BARRY, W. C. \& IRVIN, A. D. (1984). Monoclonal antibody neutralizes the sporozoite stage of different Theileria parva stocks. Parasite Immunology 6, 361-370.

Dobbelaere, D. A. E., Webster, P., Leitch, B. L., Voigt, W. P. \& IRVIN, A. D. (1985). Theileria parva: expression of a sporozoite surface coat antigen. Experimental Parasitology 60, 90-100.

KNight, P., Musoke, A. J., GaChanJa, J. N., NENE, V., KATZER, F., BOUlter, N., Hall, R., BROWN, C. G. D., WILliamson, S., KIRVAR, E., BELl-SAKYI, L., HUSSAIN, K. \& TAIT, A. (1996). Conservation of neutralising determinants between the sporozoite surface antigens of Theileria annulata and Theileria parva. Experimental Parasitology 82, 229-241.

KING, L. A. \& POSSEE, R. D. (1992). The Baculovirus Expression System: A Laboratory Guide. Chapman and Hall, London.

LAEMMLI, U. K. (1970). Cleavage of structural protein during the assembly of the head of bacteriophage T4. Nature, London 227, 680-685.

LI, Y., LUO, L., ThOMAS, D. Y. \& KANG, C. Y. (1994). Control of expression, glycosylation and secretion of HIV-1 gp120 by homologous and heterologous signal sequences. Virology 204, 266-278.

LUCKOW, V. A., LEE, S. C., BARRY, G. F. \& OLINS, P. O. (1993). Efficient generation of infectious recombinant baculoviruses by site-specific transposon-mediated insertion of foreign genes into a baculovirus genome propagated in Escherichia coli. Fournal of Virology 68, $4566-4579$.

MUSOKe, A. J., NANTUlya, V. M., RURANGIRWA, F. R. $\&$ BUSCHER, G. (1984). Evidence for a common protective antigenic determinant on sporozoites of several Theileria parva strains. Immunology 52, 231-238.

MUSOKE, A. J., NENE, v. \& McKeEver, D. (1995). Epitope specificity of bovine immune responses to major surface antigen of Theileria parva sporozoites. In Vaccines (ed. Chanock, R. M., Brown, F., Ginsberg, H. S. \& Norry, E.), 95, 57-61. Cold Spring Harbor Laboratory Press, Cold Spring Harbor, New York.

MUSOKE, A. J., MORZARIA, S., NKONGE, C., JONEs, E. \& NENE, V. (1992). A recombinant sporozoite surface antigen of Theileria parva induces protection in cattle. Proceedings of the National Academy of Sciences, USA 89, 514-518.

NENE, V., GOBRIGHT, E., BISHOP, R., MORZARIA, S. \& MUSOKE, A. (1999). Linear peptide specificity of bovine antibody responses to p67 of Theileria parva and sequence diversity of sporozoite-neutralising epitopes: Implication for a vaccine. Infection and Immunity 67, 1261-1266.

NENE, V., IAMS, K. P., GOBRight, E. \& MUSOKE, A. J. (1992). Characterisation of the gene encoding a candidate vaccine antigen of Theileria parva sporozoites. Molecular Parasitology 51, 17-28.

Nene, V., inumaru, S., McKeever, D., MorZaria, S., Shaw, M. \& MUSOKE, A. (1995). Characterization of an insect cell-derived Theileria parva sporozoite vaccine antigen and immunogenicity in cattle. Infection and Immunity 63, 503-508.

Nene, V., Musoke, A., Gobright, E. \& Morzaria, s. (1996). Conservation of the sporozoite p67 vaccine antigen in cattle derived Theileria parva stocks with different cross-immunity profiles. Infection and Immunity $\mathbf{6 4}$, 2056-2061. 
NORVAL, R. A. I., PERRY, B. D. \& YOUnG, A. S. (1992). The Epidemiology of Theilerosis in Africa. Academic Press Limited, London.

PELlÉ, R. \& MURPHY, N. B. (1993). Northern hybridization: rapid and simple electrophoretic conditions. Nucleic Acids Research 21, 2783-2784.

REIlanders, H., HAASE, W. \& MAUl, G. (1996). Functional expression of the Aquorea victoria green fluorescent protein in insect cells using the baculovirus expression system. Biochemistry and Biophysics Research Communications 219, 14-20.

RUCKER, E., SCHNEIDER, G., STEINHAUSER, K., LOWER, R., HAUbER, J. \& STAUBER, R. H. (2001). Rapid evaluation and optimisation of recombinant protein production using GFP tagging. Protein Expression and Purification 21, 220-223.

SATO, T., HANADA, M., BODRUG, S., IRIE, S., IWANA, N., BoIse, L. H., THOMPSON, C. B., GOLEMI, S. E., FONG, L., WANG, H. G. \& REED, J. C. (1994). Interactions among members of the Bcl-2 protein family analysed with a yeast two-hybrid system. Proceedings of the National of Academy Sciences, USA 91, 9238-9242.

SEDLAK, T. W., OLTVAI, Z. N., YANG, E., WANG, K., BOISE, L. H., THOMPSON, C. B. \& KORSMEYER, S. J. (1995). Multiple Bcl-2 family members demonstrate selective dimerizations with Bax. Proceedings of the National Academy of Sciences, USA 92, 7834-7838.

ShaW, M. K., TILnEY, L. G., MUSOKE, A. J. \& TEALE, A. J. (1995). MHC class I molecules are an essential cell surface component involved in Theileria parva sporozoite binding to bovine lymphocytes. Fournal of Cell Science 108, 1587-1596.

SMITH, G. E., VLAK, J. M. \& SUMMERS, M. D. (1983). Physical analysis of Autographa califonica nuclear polyhedrosis virus transcripts for polyhedrin and 10000 molecular-weight protein. Fournal of Virology 45, 215-225.

STAUber, R. H., AFONina, E., GULNiK, S., ERICKSON, J. \& PAVlakis, G. N. (1998 a). Analysis of intracellular trafficking and interactions of cytoplasmic HIV-1 Rev. mutants in living cells. Virology 251, $38-48$.

STAUber, R. H., horie, K., CARney, P., HUdSon, E. A., TARASOVA, N. I., Gaitanaris, G. A. \& PaVlakis, G. N. $(1998 b)$. Development of and applications of enhanced green fluorescent protein mutants. BioTechniques 24, 462-471.

SUMMERS, M. D. \& SMITH, G. E. (1987). A manual of methods for baculovirus and insect cell culture procedures. Texas Agricultural Experiment Station Bulletin, 1555.

TSIEn, R. (1998). The green fluorescent protein. Annual Review of Biochemistry 67, 507-544.

WALDO, G. S., STANDISH, B. M., BERENDZEN, J. \& TERWILliger, T. C. (1999). Rapid protein-folding assay using green fluorescent protein. Nature Biotechnology 17, 691-695.

Wilson, L.E., WILKINSON, N., MARLOW, S. A., POSSEe, R. D. \& KING, L. A. (1997). Identification of recombinant baculoviruses using green fluorescent protein as a selectable marker. BioTechniques 22, 674-681. 